\title{
Análisis de la evolución de la jurisprudencia del Tribunal Europeo de Derechos Humanos sobre el discurso del odio
} Analysis of the evolution of the case law of the European Court of Human Rights on hate speech

Valiente Martínez, Francisco

Universidad Pontificia de Comillas fvaliente@comillas.edu

\section{Forma de citar este artículo:}

Valiente, F. (2019). “Análisis de la evolución de la jurisprudencia del Tribunal Europeo de Derechos Humanos sobre el discurso del odio", RAEIC, Revista de la Asociación Española de Investigación de la Comunicación, vol. 6, núm. 12, 230-249.

\section{Resumen:}

El Tribunal Europeo de Derechos Humanos es la más alta jurisdicción en materia de protección de las libertades reconocidas por el Convenio Europeo de Derechos Humanos. Ejerce sus potestades conjugando dos criterios, el carácter universal de los mismos y el margen de apreciación nacional. En el ámbito del discurso del odio, el TEDH ha tenido que analizar cuáles son los límites de la libertad de expresión, generando una amplia y diversa jurisprudencia que, en muchos casos, no ha estado exenta de polémica.

Palabras clave: Tribunal Europeo de Derechos Humanos, discurso del odio, libertad de expresión, margen de apreciación nacional, límites a los derechos fundamentales. 


\section{Abstract:}

The European Court of Human Rights is the highest jurisdiction for the protection of the liberties recognized by the European Convention on Human Rights. The Court exercises its powers by combining two criteria: the universal nature of these rights and the margin of national appreciation. In the field of hate speech, the ECHR has had to analyze what are the limits of freedom of speech, generating a broad and diverse jurisprudence that, in many cases, has not been free from controversy.

Keywords: European Court of Human Rights, hate speech, freedom of speech, margin of national appreciation, limits of fundamental rights.

\section{INTRODUCCIÓN}

Recién acabada la II Guerra Mundial, Winston Churchill escribió: “Pido a las naciones de Europa, entre las cuales han fluido ríos de sangre, que olviden las hostilidades de mil años". Esta aspiración era compartida por millones de ciudadanos europeos, quienes soñaban con una coexistencia pacífica entre sus diversos países y desterrar para siempre las atrocidades sufridas durante la primera mitad del siglo XX.

Así nació el Consejo de Europa, una entidad de carácter supranacional cuyo fin es promover la cooperación y colaboración de los distintos Estados del Viejo Continente y configurar un espacio sustentando el respeto a la democracia, el imperio de la ley y la protección de los derechos humanos.

En esta última misión, destaca por encima de cualquier otra institución el Tribunal Europeo de Derechos Humanos, sito en Estrasburgo (en adelante, el TEDH). Aunque ha venido desempeñando su labor desde 1954, el TEDH tal y como lo conocemos hoy comenzó a funcionar el 1 de noviembre de 1998, día en que entró en vigor el Protocolo 11 del Convenio para la Protección de los Derechos Humanos y Libertades Fundamentales.

El discurso del odio comenzó a ser un problema preocupante para el Consejo de Europa desde muy pronto. Ya la Recomendación 453 (1966) sobre Medidas a tomar contra la 
incitación al odio racial, nacional y religioso señala la existencia de peligros causados por la existencia y difusión de mensajes de carácter discriminatorio, fóbico o amenazador contra colectivos en riesgo de exclusión.

Pero no fue hasta la Recomendación R (97) 20 del Comité de Ministros, de 30 de octubre de 1997, que el discurso del odio cobrara forma como concepto jurídico propio, concepto que engloba "todas las formas de expresión que difundan, incitan, promuevan o justifican el odio racial, la xenofobia, el antisemitismo u otras formas de odio basadas en la intolerancia, incluyendo la intolerancia expresada por nacionalismo agresivo y etnocentrismo así como la discriminación y hostilidad contra las minorías, los migrantes y las personas de origen inmigrante".

Estudiar el tratamiento que da el TEDH al discurso del odio exige hacer tres tipos de precisiones previas: En primer lugar, hay que hacer mención a los criterios genéricos que aplica el Tribunal cuando dicta sus sentencias; en segundo lugar, hay que analizar qué ha decidido el TEDH acerca de los límites a la libertad de expresión y, en tercer lugar, hay que evaluar cómo trata el discurso del odio en sus diferentes manifestaciones.

\section{LOS CRITERIOS DE FUNCIONAMIENTO DEL TEDH}

El objetivo fundacional del TEDH y su metodología de funcionamiento constituyen un caso de éxito extraordinario: en la actualidad, 47 países que muchas veces fueron enemigos aceptan la competencia de un órgano supranacional que se arroga la potestad de proteger, en última instancia, los derechos fundamentales de sus habitantes y corregir en no pocas ocasiones a sus más altos tribunales nacionales. Es una fórmula que funciona, como se demuestra por el hecho de que cada año se presentan más de cincuenta mil nuevas demandas.

En Europa hemos comprobado de primera mano los abominables crímenes que un Estado puede cometer contra su propia población y también el proceso que llevaba a democracias técnicamente perfectas, como la República de Weimar, a degenerar en tiempo récord para convertirse en regímenes totalitarios. Resultaba lógico que la dignidad humana se convirtiese entonces en la piedra angular de nuestra gran 
institución judicial. La dignidad se interpreta como una "noción prejurídica que refleja una cualidad intrínseca al ser humano y que constituye el fundamento de los demás derechos". (Ochoa 2019, p. 213) Este carácter fundamental de la dignidad como punto de partida en la interpretación de los derechos humanos siempre ha estado presente en los tribunales supranacionales europeos y no puede perderse de vista en ningún análisis que se haga sobre el TEDH.

Pero si analizamos el funcionamiento del Tribunal, enseguida constatamos que su gran particularidad, y quizás gran mérito también, es que debe equilibrar un patrón común de actuación con la realidad de las diferentes naciones que están bajo su jurisdicción. Es por eso que, al desarrollar su labor, ha venido construyendo unos estándares mínimos de actuación y los ha conjugado con el llamado margen de apreciación nacional, es decir, un espacio propio para la legislación de cada país (Freixes, 2005, p. 75 y ss.).

Lo que se está produciendo en Europa es un diálogo complejo, estructuralmente asimétrico y diversificado entre el TEDH, los tribunales nacionales ordinarios y los tribunales constitucionales y supremos de los países que firmantes del Convenio. Se trata de "un gran crisol de experiencias jurídicas muy variadas: un estupendo laboratorio sobre derechos", de tal guisa que todos y cada uno de estos actores está contribuyendo, con cada sentencia relativa a los derechos humanos, a configurar un espacio jurídico común. (García Roca, 2010, p. 51 y ss.).

¿Cómo se está desarrollando este diálogo? O, lo que es lo mismo, ¿cuáles son los criterios conforme a los que el TEDH resuelve sus casos? El primer principio es la universalización de los derechos humanos: para el TEDH este principio es irrenunciable y el origen de toda su actuación. Existe un mínimo común, un núcleo esencial de cada derecho que no se puede ver nunca vulnerado, porque ello supondría desnaturalizar su mera existencia y anularlo a efectos prácticos.

Por otro lado, tenemos el criterio del margen de apreciación nacional, un concepto jurídico indeterminado que depende de la casuística y que se desarrolla de una forma u otra atendiendo a una serie de circunstancias particulares (Pascual, 2013, pp. 217-225). Este criterio se aplica cuando el TEDH, por la razón que sea, entiende que las 
restricciones a derechos que han aprobado los parlamentos de un país concreto tienen perfecto sentido en su contexto y su realidad nacional y que, por lo tanto, las decisiones que los órganos judiciales patrios hayan tomado para resolver sus propios asuntos aplicando dichas leyes nacionales son conformes al Convenio, aunque no necesariamente extrapolables a otros países ni universalizables.

Este principio puede parecer, y de hecho es, razonable. Pero no está exento de críticas, pues se trata de un constante ejercicio de equilibrismo que hubiese firmado el mejor malabarista. No existe un criterio, una doctrina o una metodología que nos permita aventurar cuándo el TEDH va a aplicar o no el margen de apreciación nacional. Ésta es la principal crítica que se hace al mismo: la falta de sistematización, que deviene en inseguridad jurídica. Se trata, pues, de un mecanismo de resolución de conflictos elaborado a golpe de sentencia. (de Montalvo, 2012, p. 151 y ss.).

De lo expuesto podemos extraer una primera conclusión: precisamente, quizás por sus imprecisiones, el sistema funciona. Con todas las críticas que se le quieran hacer, la discrecionalidad a la hora de aplicar el margen de apreciación nacional permite al TEDH trabajar con considerable flexibilidad y así analizar cada caso de forma individualizada, sin que el margen de apreciación que se entiende válido en un contexto tenga que determinar la respuesta a algún asunto que tenga su origen en otro país.

\section{LA INTERPRETACIÓN QUE DA EL TEDH AL DERECHO A LA LIBERTAD DE EXPRESIÓN}

Entrando en el tema que nos ocupa: ¿Cómo ha tratado el TEDH los límites a la libertad de expresión? Estrasburgo siempre ha considerado a este derecho como un valor preferente y fundamental en una sociedad democrática, derecho que, no obstante, no es absoluto y que puede ser sometido a límites concretos (Costa, 2001,p. 249). Así se recoge expresamente en el caso Erbakan v. Turquía (2006): "La igualdad y el respeto por la igual dignidad de todos los seres humanos constituyen los cimientos de una sociedad democrática y pluralista. En estas condiciones, en determinadas sociedades democráticas puede considerarse necesario sancionar o incluso impedir toda forma de expresión que difunda, fomente, promueva o justifique el odio basado en la intolerancia, siempre que [...] sean proporcionadas al objetivo legítimo perseguido". 
De manera que podemos afirmar que el TEDH entiende que las sociedades democráticas no se fundamentan exclusivamente sobre las libertades individuales, sino que su gran soporte ha de ser la tolerancia y el pluralismo. Pero ello nos obliga a hacernos una pregunta: ¿Tolerancia con qué? ¿Con las sensibilidades de las minorías y con sus particularidades religiosas y culturales? ¿O tolerancia de dichos individuos, pertenecientes a dichos colectivos minoritarios, con el hecho de que forman parte activa y viven en un sistema de libertades y que, por ende, tienen que aceptar pensamientos y opiniones críticas y discrepantes? Como se ve, la respuesta a esta cuestión parece estar sometida siempre al cristal con que se mire.

Todo ello exige un profuso e ingente trabajo a la hora de delimitar los derechos fundamentales y, en particular, el derecho a la libertad de expresión. En este sentido, el propio texto del Convenio es muy claro, pues el artículo 10.2 recoge límites expresos: la seguridad nacional, la integridad territorial, la seguridad y el orden público, la prevención del delito, la protección de la salud o de la moral, la protección de la reputación o de los derechos ajenos, la no divulgación de informaciones confidenciales y la protección de la autoridad y la imparcialidad del poder judicial.

A priori, todos estos límites, vistos en abstracto, pueden parecer no sólo necesarios, sino también adecuados. Pero, en la práctica, se hace evidente que no se puede estar ejerciendo legítimamente un derecho fundamental y, al mismo tiempo y por el mismo hecho, estar cometiendo un delito o algún tipo de actividad por la cual los tribunales puedan imponer una sanción. Por ello, además de estos límites propios, el TEDH entiende que la libertad de expresión es un derecho susceptible de ser ejercido de forma incorrecta o abusiva y, por lo tanto, susceptible de ser coartado por el artículo 17 del Convenio, que prohíbe específicamente el abuso del derecho (es decir, ejercer una libertad de manera tal que tenga como resultado un daño intolerable para otros derechos y libertades o para bienes jurídicos colectivos que merecen especial protección).

Entre el uso legítimo y el abuso del derecho hay una zona fronteriza, un estrecho margen donde resulta necesario determinar qué criterios emplea el TEDH para definir cuándo 
una legislación nacional está causando una vulneración controvertida del derecho a la libertad de expresión. Esta vulneración será considerada contrario al Convenio y, por lo tanto, nula, si adquiere tal gravedad que el asunto ya no se puede considerar una cuestión nacional sino una violación de ese marco común irrenunciable y universal de los derechos fundamentales.

Estos criterios se han venido a denominar "el triple test de Estrasburgo" y se pusieron claramente de manifiesto en el caso Handyside v. Reino Unido (1974). Cuando una norma nacional supera el Test de Estrasburgo significa que el límite que imponía a la libertad de expresión resulta válido porque cumple tres condiciones:

1) El límite está recogido en la ley

2) El límite es necesario para conseguir un fin legítimo en una sociedad democrática

3) Los medios empleados resultan proporcionales en relación con dicho fin

Este mecanismo permite, de facto, evaluar no sólo la literalidad de un mensaje potencialmente ofensivo, sino también su contexto, es decir, la forma en que se expresa, la intencionalidad del autor, su previsible impacto pernicioso y, si procede, la contundencia de la sanción aplicada conforme a las leyes nacionales (Valero, 2017, p. 311-312).

Lo que queda patente en estos casos es que la libertad de expresión puede entrar frecuentemente en colisión con otros derechos, como el honor (individual o colectivo) o contra otros valores o bienes que merecen protección, como la pretensión general de respeto o la paz social. $Y$ en este sentido, el discurso del odio tiene una relevancia nuclear pues, aunque el pensamiento no delinque, no es menos cierto que las palabras rara vez son inocentes.

\section{EL TEDH ANTE LOS DISTINTOS TIPOS DE DISCURSO DEL ODIO}

\subsection{LOS MENSAJES EXTREMISTAS}


Es un hecho constatable que el TEDH nunca ha entrado en analizar si las manifestaciones fóbicas, discriminatorias o incitadoras al odio tienen o no un fundamento de veracidad o aportan algo al debate público; no condiciona su represión a que haya un riesgo cierto de comisión de delitos ni tampoco ha considerado como un elemento fundamental la difusión que pueda alcanzar el mensaje para evaluar su carácter dañino. (Díaz Soto, 2015, p. 98). Dicho de otro modo: el Tribunal entiende que el discurso del odio no forma parte del derecho a la libertad de expresión y que, por ende, merece castigo por parte de las leyes nacionales.

Por otro lado, la jurisprudencia parece admitir dos tipos de discurso del odio en función de la gravedad de su contenido: por un lado, el que resulta genuinamente extremista y constituye un atentado contra las propias nociones de democracia y libertad; por otro, estarían las expresiones que se convierten en discurso del odio por el punto de vista ofensivo que el emisor emplea para tratar alguna cuestión de carácter polémico o que afecte a colectivos en riesgo de exclusión (Esquivel, 2016, p. 11).

Respecto al primer escenario, un caso particularmente representativo podría ser el asunto Gundüz v. Turquía (2003), que ratificó la condena que los tribunales turcos impusieron a un imán que defendía la supresión del régimen democrático, la implantación de la Sharia y la legitimación de la Yihad, por ser los únicos valores verdaderos, frente a la hipocresía de la democracia, donde bajo la falacia de la falsa libertad convivían la verdad y la mentira.

Respecto al segundo caso, el TEDH ha ido intentando delimitar qué es y qué no es discurso del odio y, en cierta medida, hasta dónde se puede castigar su expresión. Los criterios varían con frecuencia tanto por las distintas modalidades de discurso del odio como por las opiniones a veces discrepantes que se han ido forjando. Por ello, para sistematizar el estudio, es preciso hacer un análisis temático que permita estudiar la evolución de la jurisprudencia y el estado actual de cada cuestión.

\subsection{ANTISEMITISMO Y NEGACIÓN DEL GENOCIDIO}

EI TEDH siempre ha mantenido que la negación y justificación del genocidio eran un abuso del derecho a la libertad de expresión y por ello ha ratificado la actuación de los 
distintos tribunales nacionales y de las leyes que castigaban estos fenómenos. En este tipo de actos, por tanto, apreciamos una clara coherencia por parte del Tribunal.

La justificación del Holocausto es el fenómeno por el cual se intenta presentar el genocidio sufrido por el pueblo judío durante el nazismo como un fenómeno lógico, fruto de su tiempo y entendible en un determinado contexto. Cuando se conocen los horrores de la "solución final", tal defensa es inmoral y causa vergüenza. El negacionismo no pretende tanto, sino que se limita a argumentar la imposibilidad de que tales hechos ocurriesen de tal modo. Por ello, hay autores que lo consideran una especie de "hijo degenerado" o "hijo cobarde" de la justificación (Teruel, 2014, p. 23 y ss.). En ambos casos, el TEDH ha legitimado prácticamente todas las todas las restricciones que las leyes y los tribunales nacionales han ido fijando. Esta tendencia jurisprudencial puede acreditarse a través del análisis de los principales casos

Witzcsh v. Alemania (1999): Hans Witzsch fue procesado por dirigir una campaña contraria a la tipificación del negacionismo en el Código Penal Alemán. Consideraba la Conferencia de Wansee y la Solución Final como una "mentira histórica", diseñada por las supuestas "falsas víctimas" de las "así llamadas" cámaras de gas, todo ello con la complicidad, hipocresía y cobardía de los políticos actuales, culpables de engañar a la población. Tras ser condenado por las leyes alemanas, apeló al TEDH. La Corte entendió que, precisamente en Alemania, sus palabras sólo podían entenderse como un desprecio hacia la dignidad de las víctimas y que las leyes que la castigaban eran acordes al Convenio.

Garaudy v. Francia (2003): Roger Garaudy era un filósofo y político francés, autor de una obra llamada Los mitos fundadores de la política israelí. Durante el desarrollo de la obra, el autor trata de demostrar que el Holocausto fue y es utilizado como herramienta propagandística por parte del sionismo para justificar no sólo la creación y existencia del Estado de Israel, sino también sus políticas agresivas, sobre todo contra los palestinos. A juicio del Tribunal, si bien durante la lectura del libro se podía deslindar con claridad la parte negacionista de lo que era un análisis de relaciones internacionales, toda comprensión global del libro conllevaba la negación del Holocausto. Se consideró, por 
tanto, que Garaudy había cometido un abuso de derecho aprovechando una cuestión controvertida de actualidad para deslizar un mensaje de odio.

Gollnisch v. Francia (2011): Bruno Gollnisch es un eurodiputado del del Frente Nacional francés y también un profesor universitario. Durante una conferencia de prensa se le preguntó su opinión sobre las leyes que tipifican el Holocausto como delito. Aunque en su respuesta no negó en ningún momento la veracidad de estos hechos históricos, planteó que el debate sobre el mismo y sus repercusiones debería estar abierto, y criticó explícitamente el informe de la Commission sur le racisme et le négationnisme à I'université Jean-Moulin Lyon III, al que calificó como sesgado, parcial y lleno no sólo de errores, sino de manifiestas falsedades. Gollnisch fue apartado temporalmente de la docencia y procesado por negacionismo, por lo que apeló al TEDH, que entendió que sus manifestaciones no habían sido hechas en su calidad de líder y representante político sino como profesor universitario, lo que le exigiría una responsabilidad adicional, pues su misión como docente es de particular relevancia social y exige que se manifieste con responsabilidad.

M'bala M'bala v Francia (2015): El polémico humorista francés, Dieudonné M'bala, de religión musulmana, con frecuencia deslizaba en sus obras mensajes antisemitas y siempre ha manifestado su ideología próxima al Frente Nacional. En uno de sus espectáculos fue invitado Robert Faurisson, un historiador que había sido condenado por negacionismo, para el cual pidió un fuerte aplauso e hizo que un figurante vestido con un pijama de rayas le entregase un premio. M'bala M'bala fue procesado y condenado, por lo que apeló al TEDH. Éste inadmitió su recurso argumentando que “disfrazada bajo la apariencia de una producción artística, esta demostración de odio es tan peligrosa como un ataque frontal y abrupto".

Estos cuatro casos resultan ilustrativos porque, en todos ellos, el TEDH ha aplicado un considerable margen de apreciación nacional y legitimado las restricciones a la libertad de expresión en supuestos que quizás debieran haberse entendido como merecedores de un mayor espacio de libertad, a saber: al criticar una ley, al analizar cuestiones sobre 
relaciones internacionales, al interpretar la libertad de cátedra y en la creación artística y humorística.

Nos encontramos ante un caso de discurso del odio cuando hay un colectivo afectado, un mensaje ofensivo y un riesgo de discriminación. Si existe la posibilidad de que se cause un daño, resulta casi instintivo compartir las sentencias del TEDH cuando pretende amparar al débil o al indefenso o defender la verdad, pero las decisiones que se están tomando en casos como los aquí expuestos, limitando la libertad de cátedra, la parodia o la crítica a las propias normas, deberían hacernos reflexionar sobre cuál es el camino adecuado o más beneficioso para la sociedad (Valiente, 2017, p. 452).

En el caso del Holocausto, la justificación de estas restricciones se encuentra en que lo que se ha venido a denominar el "hecho históricamente incontestable", que sería aquel cuya negación no puede entenderse como fruto de la ignorancia o la inocencia, sino como fruto de un interés oculto para blanquear lo que fue una espantosa realidad. (Bilbao, 2017, p. 334).

Sin duda esta premisa permitiría argumentar las restricciones a la libertad de expresión pero, a mi modo de ver, presenta un aspecto sumamente criticable: ¿cuántos hechos históricamente incontestables hay? Por ejemplo, es igualmente incontestable que las mujeres no han estado en situación de igualdad de oportunidades con los hombres durante siglos... ¿ ¿estarían entonces protegidos por la libertad de expresión los discursos críticos con el feminismo o serían considerados justificación encubierta de la discriminación? Si de lo que se trata es de ir encontrando categorías que permitan dar un trato objetivo al discurso del odio, este tipo de construcciones no resultan tan sólidas como pudiera parecer.

Por ello, quizás un camino más seguro sea que el delito de negación del Holocausto se entremezcle con el concepto de negación del genocidio, y que aceptemos como genocidios, a efectos jurídicos, sólo los actos que así hayan sido catalogados por un Tribunal Penal Internacional con jurisdicción para ello (Bustos, 2015, p. 145 y ss.). El problema es que esto reduce considerablemente la lista de genocidios, que serían tan solo el Holocausto y los vividos en Ruanda, Yugoslavia y quizás Birmania. El resto de 
circunstancias históricas que reúnan las características del genocidio podrían calificarse como "hechos equiparables", pero sólo a efectos historiográficos o, al menos, no desde luego a efectos judiciales. Se trata de un criterio reduccionista, es verdad, pero jurídicamente objetivo y garante de una considerable seguridad.

\subsection{HOMOFOBIA}

Al contrario de lo que acabamos de comentar, el Tribunal de Estrasburgo sí ha vivido una complejísima evolución en el tratamiento de la homofobia, comenzando por entender legítimas las leyes penales que castigaban esta conducta hasta una considerable protección y reconocimientos de los derechos del colectivo LGTBIQ+.

El primer paso, que hoy puede causar estupefacción, se dio cuando el Tribunal apenas llevaba un año en funcionamiento. En el caso $X$ v. R.F.A. (1955) un ciudadano alemán solicitó la anulación de las leyes penales que castigaban la homosexualidad entre adultos mayores de 21 años. Su pretensión y otras similares presentadas por ciudadanos alemanes fueron rechazadas porque "el Convenio permite a un Estado contratante penalizar la homosexualidad, pues el derecho al respeto de la vida privada puede ser objeto, en una sociedad democrática, de una injerencia prevista por la ley para la protección de la salud y de la moral" ${ }^{1}$

No fue hasta el caso Dudgeon v. Reino Unido (1981) que se declaró por fin que dichas sanciones violaban el Convenio y debían desaparecer. Y no fue hasta el caso Salgueiro Da Silva Mouta v. Portugal (1999), que el TEDH reinterpretó el artículo 14 del Convenio, que prohíbe toda forma de discriminación, para considerar la homofobia como un tipo de discriminación que debía ser perseguida y eliminada. La tardanza en aceptar estos postulados nos permite concluir que, en lo referido a la homofobia, el TEDH no ha sido motor del cambio, sino que más bien ha ido a rebufo de los logros que se iban consiguiendo en otros ámbitos sociales.

\footnotetext{
${ }^{1}$ En estos casos se daba la terrible circunstancia de que los afectados ya habían sido condenado por homosexualidad durante el nazismo y habían estado por ello en campos de concentración. Tras la caída del III Reich, volvieron a ser condenados, se entendió que eran reincidentes y en algunos casos las penas alcanzaron los 12 años de prisión. Alemania no modificó su ley hasta 1969, sin que mediase en ello exigencia alguna del TEDH.
} 
Pero el proceso dista aún de haber concluido. El reconocimiento público de la homosexualidad ha seguido encontrando numerosas trabas en muchos países, particularmente en el este de Europa. Aquí sí podemos decir que, finalmente, el TEDH se ha pronunciado con contundencia: en el caso Baczkowski y otros v. Polonia (2007), las medidas tomadas por las autoridades polacas para impedir una manifestación por las calles de Varsovia de varias asociaciones del colectivo LGTBIQ+ fueron declaradas contrarias al Convenio. Criterio que se mantuvo cuando en el asunto Alekseyev v. Rusia (2010) se entendió que tomar medidas administrativas para prohibir la celebración pública del Día del Orgullo Gay vulneraban desproporcionadamente derechos fundamentales.

El último paso se ha dado más recientemente al analizar las leyes rusas que penalizan la propaganda de la homosexualidad. En el caso Bayev y otros v. Rusia (2017), se ha señalado que afrontamos "un conflicto entre la libertad de expresión y el derecho a la privacidad [...] y la autoidentificación de las personas": Sin embargo, en este conflicto, en ningún caso puede acreditarse que el reconocimiento de la homosexualidad y su publicidad vulneren la moral pública ni que la libertad de expresión acerca de los temas LGBTIQ+ devalúe efectivamente o ponga en riesgo a las familias tradicionales.

Si bien se ha pasado de legitimar la penalización de la homofobia a castigar la prohibición de su pública expresión, queda, para algunos autores, aún un paso por dar: la plena consideración de las uniones homosexuales como matrimonio (Borrillo, 2011, pp. 8990). Sin embargo, aquí el TEDH sigue considerando que es aplicable el margen de apreciación nacional y que corresponde a cada país decidir si equipara o no las uniones de hecho con el matrimonio, por lo que el concepto tiene de elemento religioso, simbólico y cultural, pues el Tribunal entiende que, a efectos prácticos, toda legitimación de la discriminación ha quedado ya superada.

\subsection{EL ODIO RELIGIOSO}

La religión históricamente ha sido tanto una guía para la espiritualidad de millones de personas como, también, una de las principales causas de conflictos. Los derechos humanos reconocieron muy pronto y expresamente el derecho a elegir libremente una 
fe $y$, por supuesto, el derecho a no ser hostigado por profesarla. Sin embargo, en la actualidad perviven muchos conflictos religiosos que generan grandes tensiones personales y sociales.

Al ser una cuestión tan controvertida y personalísima, pues la fe no deja de ser la forma en la cual cada individuo interpreta su concepción del mundo y de su propia existencia, el término más adecuado para referirnos al bien jurídico protegido es el de la "sensibilidad" de los sujetos. En términos generales, los Estados laicos y aconfesionales han ido abandonando el delito de blasfemia, que sería el insulto a Dios o a lo sagrado, pero en muchos aún pervive el delito de ofensa a las sensibilidades religiosas. Dicho delito protege no la dignidad divina sino los sentimientos de los fieles, con el fin de que lo que a ellos resulta sagrado sea respetado. Pero a esta cuestión se le ha dado también un enfoque adicional: es una cuestión de orden público.

En estos casos, el TEDH suele seguir un triple razonamiento: en primer lugar, considera a las confesiones religiosas como agrupaciones a las que los individuos se adhieren libremente; en segundo lugar, declara parte del contenido esencial de este derecho el no ser discriminado por profesar una u otra fe, o ninguna; en tercer lugar, deja un notable margen de apreciación nacional para que sea cada país quien resuelva los demás aspectos polémicos como mejor considere (Arlettaz, 2012, p. 213).

En lo referido al discurso del odio y la ofensa a las libertades religiosas, uno de los primeros casos fue Otto Preminger Institut v. Austria (1985). El Instituto Otto Preminger anunció la emisión de la película "El concilio del amor", de contenido claramente irreverente (se presentaba a Dios como un anciano senil, a Jesucristo como malcriado y a la Virgen teniendo una aventura con Satán). Los tribunales austriacos entendieron que esta película suponía una ofensa contra las sensibilidades religiosas, y así lo ratificó el TEDH, para quien "las autoridades austriacas actuaron para proteger la paz religiosa en esta región y para impedir que muchos se sintieran atacados en sus sentimientos religiosos de manera injustificada y ofensiva".

Incluso aunque diversos organismos del Consejo de Europa han solicitado despenalizar la blasfemia, el TEDH siempre ha dejado un considerable margen de apreciación 
nacional en este asunto. La prueba la tenemos en el caso Wingrove v. Reino Unido (1996), al que se llegó después de que la British Board of Film Classification no autorizase la distribución de una película basada en la vida de Santa Teresa de Jesús por considerarla blasfema, ya que se mezclaba el misticismo de la protagonista con una fuerte pasión sexual.

Este criterio proteccionista con las sensibilidades religiosas también se ha aplicado en el caso del Islam. En el asunto Aydin Tatlav v. Turquía (2006), los tribunales turcos prohibieron un libro que presentaba algunos pasajes ciertamente hirientes para la fe mahometana. Tras consultar con algunos imanes, las autoridades turcas decidieron prohibir la obra y condenar al editor por blasfemia.

Pero, ¿̇hasta qué punto un mensaje es ofensivo para una sensibilidad religiosa? Si cada persona tiene su propia sensibilidad, esta cuestión no es menor. Podría tomarse como criterio si un mensaje sirve para fomentar el debate público o si, por el contrario, lo que hace es socavar otros derechos. ¿Pero dónde está esa fina frontera? Sin duda, no hay un concepto uniforme para delimitarla (Ferreiro, 2006, p. 37).

Por ello, me resulta particularmente preocupante el último caso analizado por el TEDH a este respecto, el asunto E.S. v Austria (2019). Elisabeth Sabaditsch-Wolff es una conferenciante que había calificado en público y de forma reiterada la relación entre Mahoma y Aisha, su quinta esposa, de pederastia. Fundamentaba esta afirmación en que, según la tradición islámica, el Profeta tenía cincuenta y tres años al contraer matrimonio y la joven seis, y que, además, éste se había consumado cuando ella contaba tan solo nueve años de edad. Los tribunales austriacos entendieron que las conferencias de la señora Sabaditsch eran constitutivas de una "denigración de doctrina religiosa", y la condena impuesta en Austria fue ratificada por el TEDH, en una sentencia que no ha estado exenta de críticas.

Para Elisabeth Sabaditsch-Wolff no sólo se trata de una violación de su libertad de expresión, sino también de una imposibilidad de decir la verdad: Argumentó que trataba al Mahoma histórico y no a su carácter como Profeta y dio un paso más y lanzó preguntas que tienen una difícil respuesta: ¿Podemos acaso defender la lucha contra el 
matrimonio infantil y no denunciar que Mahoma era pedófilo? ¿Se puede condenar el recordar hechos históricos establecidos cuando estos conciernen a una personalidad considerada sagrada por una religión? Si en vez de Mahoma se hubiese hecho un comentario similar sobre Jesucristo... ¿la sentencia habría sido la misma?

A mi modo de ver, el Tribunal está adoptando una senda de difícil retorno e incluso está desoyendo las recomendaciones de otros organismos consultivos, como la Comisión de Venecia. Fue en el seno de la misma cuando se planteó que, sin duda, tipificar la blasfemia o la ofensa a las sensibilidades religiosas suponía una merma a la libertad de expresión, pero no ocurría así a la inversa, pues permitir este tipo de mensajes no mermaba en nada las libertades religiosa y de culto, sino que únicamente algunos fieles podrían sentirse molestos (Kovacs, 2015).

\subsection{IDEOLÓGICO}

Junto a los casos ya expuestos, puede resultar de interés realizar una aproximación al concepto de odio ideológico, toda vez que es uno de los aspectos en los cuales España se ha visto en más ocasiones afectada por las resoluciones del TEDH.

En términos generales, Estrasburgo siempre ha considerado que la apología del terrorismo y la incitación al mismo se situaban fuera de la protección de la libertad de expresión. En este sentido, se acepta que el mensaje terrorista puede llegar a muchos individuos y que ello lo hace esencialmente peligroso y merecedor de castigo penal (Martínez Vázquez, 2018, p. 51).

Sin embargo, no se ha mantenido este mismo criterio cuando se trataba de proteger símbolos nacionales e institucionales propios del sistema democrático. En este sentido, tanto en los casos Castells v. España (1992) como en Otegi Mondragón v. España (2011) y en Stern Taulats y Roura Capellera v. España (2018), nuestro país ha salido mal parado. Castells y Otegi eran políticos en activo que vertieron muy duros comentarios contra los Cuerpos y Fuerzas de Seguridad del Estado, contra el Rey y contra otras instituciones democráticas, hechos por los que fueron condenados por los tribunales españoles. Sin embargo, el TEDH entendió que estas restricciones frenaban el libre debate político, por lo que dio la razón a los demandantes. Por su parte, Roura y Stern eran dos jóvenes que 
clausuraron una manifestación antimonárquica en Gerona quemando públicamente una gran foto del Rey Juan Carlos I; procesados por injurias a la Corona, el TEDH entendió que este hecho era una manifestación de su libertad ideológica y que habían sido castigados de forma excesiva.

Traigo estos hechos a colación por suponer un contraste con otros casos, en concreto Féret v. Bélgica (2009) y Rujak v. Croacia (2012). En el primero de ellos, un político belga del Frente Nacional concurrió a unas elecciones con un programa electoral de marcado tinte islamófobo, tildando a los líderes de la comunidad musulmana como "cus-cús klan" y clamando para que las ayudas públicas destinadas a extranjeros se diesen a belgas en situación de necesidad. En el segundo caso, un soldado croata fue condenado a prisión por verter insultos contra sus oficiales, su país y las fuerzas armadas, de manera que acabó siendo condenado por atentar contra el honor nacional. En ambos casos, el TEDH entendió que, tras aplicar su triple test, las sanciones eran legítimas y correspondía aplicar el margen de acción nacional.

Este contraste nos permite preguntarnos qué diferencias sustanciales vio el TEDH para proteger a Castells, Otegi, Roura y Stern, pero no dar la razón a Féret o Rujak. En modo alguno planteo que se trate de una especie de ataque contra España por parte del TEDH, es importante dejar esto claro. Pero, ¿por qué no considera el TEDH que estos asuntos fuesen una cuestión interna de nuestro país y no aplicó el margen de apreciación nacional? A mi modo de ver, hay dos motivos: por un lado, por el carácter discrecional antes comentado de este principio...

Pero también considero que, del mismo modo que el TEDH asume que en Alemania es imprescindible penar el Holocausto por ser la superación de estos hechos parte de su ADN democrático, o que Croacia, por ser una nación joven, necesitaba reforzar sus instituciones, o que la islamofobia creciente en Bélgica exigía medidas concretas para garantizar la paz social, Estrasburgo no parece considerar que España tenga en su ADN democrático la superación del terrorismo etarra, ni que buena parte de la población vasca viviese durante años con miedo, ni que los monárquicos que puedan vivir en 
Gerona se pudiesen sentir intimidados tras la quema de sus símbolos. ¿Por qué existe tal percepción? Dejo a su libre imaginación la respuesta.

\section{CONCLUSIONES}

Conclusión primera: El Tribunal Europeo de Derechos Humanos nunca ha considerado el discurso del odio como parte del derecho a la libertad de expresión, por lo tanto, siempre tiende a ratificar los límites que lo restringen y las sentencias que castigan a sus emisores por ser lesionar la dignidad humana.

Conclusión segunda: Aplica para ello el margen de apreciación nacional, es decir, deja la elección de la pena y la regulación específica a cada país firmante del Convenio, siempre y cuando la restricción cumpla un triple objetivo: estar fijada por la ley, ser necesaria para conseguir un fin legítimo y resultar proporcional en su aplicación.

Conclusión tercera: El TEDH evalúa las restricciones a la libertad de expresión, es decir, limita los límites de la misma (valga la redundancia). Pero como la libertad de expresión se puede dar en múltiples campos (creación artística, comercial, libertad de cátedra, discurso político, etc...) entonces puede haber una gran multitud de límites y resulta muy complejo establecer parámetros claros y criterios objetivos que midan la acción del TEDH.

Conclusión cuarta: Además, el TEDH tiene la facultad de ir evolucionando sus criterios jurisprudenciales, de tal forma que es capaz de adaptarse a distintos momentos, escenarios y contextos. Aunque ello pueda redundar en cierta inseguridad jurídica, le da un amplio margen de actuación.

\section{REFERENCIAS BIBLIOGRÁFICAS}

Arlettaz, F. (2012). La jurisprudencia del Tribunal Europeo de Derechos Humanos sobre la libertad religiosa: un análisis jurídico-político. Derechos y libertades: Revista del Instituto Bartolomé de las Casas, 16, 209-240. 
Bilbao Ubillos. (2009). La negación de un genocidio no es una conducta punible (comentario de la STC 235/2007). Revista española de derecho constitucional, 29, 299352.

Borrillo, D. (2011). De la penalización de la homosexualidad a la criminalización de la homofobia: el Tribunal Europeo de Derechos Humanos y la orientación sexual. Revista de estudios jurídicos, 11, 69-94.

Bustos, R. (2015). Libertad de expresión y discurso negacionista. En Libertad de expresión y discursos del odio (123-147). Alcalá de Henares: Universidad de Alcalá, Servicio de Publicaciones.

Costa, J. P. (2001). La libertad de expresión según la jurisprudencia del Tribunal Europeo de Derechos Humanos de Estrasburgo. Persona y derecho: Revista de fundamentación de las Instituciones Jurídicas y de Derechos Humanos, 44, 243-250.

De Montalvo, F. (2012). El difícil equilibrio entre la globalización de los derechos y su contextualización desde la perspectiva de la doctrina del margen de apreciación nacional. Estudios de Deusto: revista de la Universidad de Deusto, 60, 133-154.

Díaz Soto, J. M. (2015). Una aproximación al concepto de discurso del odio. Revista Derecho del Estado, 34, 77-101.

Esquivel, Y. (2016). El discurso del odio en la jurisprudencia del Tribunal Europeo de Derechos Humanos. Cuestiones constitucionales: revista mexicana de derecho constitucional, 35, 3-44.

Ferreiro J. (2006). Las caricaturas sobre Mahoma y la jurisprudencia del Tribunal Europeo de los Derechos Humanos. Revista electrónica de estudios internacionales (REEI).

Freixes, T. (2005). Derechos fundamentales en la Unión Europea. Evolución y prospectiva: la construcción de un espacio jurídico europeo de los derechos fundamentales. Revista de derecho constitucional europeo, 4, 43-86 
García Roca, F. J. (2010). El margen de apreciación nacional en la interpretación del Convenio Europeo de Derechos Humanos. Cizur Menor: Civitas.

Kovács, K. (2015). A brief overview of the 'constitutional balancing' between free speech and protected interests connected to religious beliefs. En: $14^{\text {th }}$ meeting of the Joint Council on Constitutional Justice, "Blasphemy and other limitations to the freedom of expression".

Martínez Vázquez, F. (2018). Cuarenta años de Constitución en la lucha contra el terrorismo. Revista ICADE. Revista de las Facultades de Derecho y Ciencias Económicas y Empresariales, 104, 36-60.

Ochoa, N. (2019). La dignidad humana como fundamento de la identidad europea: la labor del Tribunal Europeo de Derechos Humanos en la delimitación de la noción de dignidad humana. Cuadernos europeos de Deusto, Extra, 2, 203-224.

Pascual, F. (2013). El margen de apreciación nacional en los tribunales regionales de derechos humanos: una aproximación consensualista. Anuario Español de Derecho Internacional, 29, 217-262.

Teruel, G. (2014). La lucha del derecho contra el negacionismo: una peligrosa frontera. Particular estudio de los ordenamientos español e italiano. Murcia: Tesis Doctoral. Universidad de Murcia.

Valero, A. (2017). Los discursos del odio. Un estudio jurisprudencial. Revista española de derecho constitucional, 37, 305-333.

Valiente, F. (2017). Límites constitucionales al discurso del odio. Madrid: Tesis Doctoral. Universidad Pontificia Comillas ICAI-ICADE. 